\title{
Alcohol consumption and low-risk drinking guidelines among adults: a cross-sectional analysis from Alberta's Tomorrow Project
}

\author{
Darren R. Brenner*, PhD (1,2); Tiffany R. Haig*, BA (3); Abbey E. Poirier, MSc (1); Alianu Akawung, MSc (3); \\ Christine M. Friedenreich, PhD (1,2); Paula J. Robson, PhD, RNutr (UK) $(3,4)$
}

This article has been peer reviewed.

Tweet this article

\begin{abstract}
Introduction: Moderate to heavy alcohol consumption is a risk factor for all-cause mortality and cancer incidence. Although cross-sectional data are available through national surveys, data on alcohol consumption in Alberta from a large prospective cohort were not previously available. The goal of these analyses was to characterize the levels of alcohol consumption among adults from the Alberta's Tomorrow Project in the context of cancer prevention guidelines. Furthermore, we conducted analyses to examine the relationships between alcohol consumption and other high-risk or risk-related behaviours.
\end{abstract}

Methods: Between 2001 and 2009, 31072 men and women aged 35 to 69 years were enrolled into Alberta's Tomorrow Project, a large provincial cohort study. Data concerning alcohol consumption in the past 12 months were obtained from 26842 participants who completed self-administered health and lifestyle questionnaires. We conducted cross-sectional analyses on daily alcohol consumption and cancer prevention guidelines for alcohol use in relation to sociodemographic factors. We also examined the combined prevalence of alcohol consumption and tobacco use, obesity and comorbidities.

Results: Approximately $14 \%$ of men and $12 \%$ of women reported alcohol consumption exceeding recommendations for cancer prevention. Higher alcohol consumption was reported in younger age groups, urban dwellers, those with higher incomes and those who consumed more red meat. Moreover, volume of daily alcohol consumption was positively associated with current tobacco use in both men and women. Overall, men were more likely to fall in the moderate and high-risk behavioural profiles and show higher daily alcohol consumption patterns compared to women.

Conclusion: Despite public health messages concerning the adverse impact of alcohol consumption, a sizeable proportion of Alberta's Tomorrow Project participants consumed alcohol in excess of cancer prevention recommendations. Continued strategies to promote low-risk drinking among those who choose to drink could impact future chronic disease risk in this population.

Keywords: alcohol, cancer, Alberta's Tomorrow Project, cohort, prevention guidelines

\section{Introduction}

Alcohol contributes substantially to various causes of mortality. Estimates suggest that, globally, alcohol is related to $25.8 \%$ of deaths due to injuries, $33.4 \%$ of deaths due to diabetes and cardiovascular disease, and $12.5 \%$ of cancer-related deaths. ${ }^{1}$ Regular alcohol consumption is a known risk factor for at least eight specific types
Highlights

- Alcohol consumption is a risk factor for a number of chronic diseases and all-cause mortality.

- Levels of alcohol consumption were reported by 31072 participants (2001-2009) in Alberta's Tomorrow Project cohort; a geographicallybased cohort of adults aged 35 to 69 years.

- Fourteen percent of men and $12 \%$ of women reported alcohol consumption exceeding recommendations for cancer prevention.

- Elevated levels of alcohol consumption were positively associated with tobacco use and other risk factors for chronic disease.

- Public health messaging should continue to promote minimal intake levels of alcohol or low-risk drinking to reduce the burden of chronic disease in Alberta.

of cancer, including oral cavity, esophagus, pharynx, larynx, female breast, stomach, liver and colorectum. ${ }^{2,3}$ The International Agency for Research on Cancer (IARC) has declared ethanol (the active metabolite of alcohol consumption) a Group 1 carcinogen to humans ${ }^{4}$, and there is sufficient evidence to suggest a dose-risk relationship between alcohol and adverse health outcomes, especially for cancer ${ }^{5-9}$, with no evidence of a threshold effect. ${ }^{2}$ Moreover, there does not seem to be any appreciable differences for

\section{Author references:}

1. Department of Cancer Epidemiology and Prevention Research, CancerControl Alberta, Alberta Health Services, Calgary, Alberta, Canada

2. Department of Oncology and Department of Community Health Sciences, Cumming School of Medicine, University of Calgary, Calgary, Alberta, Canada

3. Cancer Measurement, Outcomes, Research and Evaluation, CancerControl Alberta, Alberta Health Services, Alberta, Canada

4. Department of Agricultural, Food and Nutritional Science, Faculty of Agricultural, Life and Environmental Sciences, University of Alberta, Calgary, Alberta, Canada

* These authors contributed equally to this work.

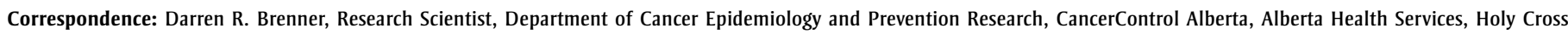
Centre, Room 514 Box ACB, 2210 2nd Street SW; Calgary, AB T2S 3C3; Email: Darren.Brenner@ahs.ca 
beverage type. ${ }^{2}$ Recent population attributable risk estimates predict that $4.2 \%$ of all incident cancer cases in the province of Alberta were attributable to alcohol consumption in $2012 .{ }^{10}$

In contrast, light-to-moderate alcohol consumption has previously been shown to have cardioprotective effects ${ }^{11-14}$ and provide protection against type II diabetes ${ }^{15,16}$ and other chronic diseases. ${ }^{14,17}$ However, recent evidence has challenged these findings and suggest that there is no safe limit of consumption, especially for cancer. ${ }^{18-21}$ Despite the controversy, identifying a safe threshold based on sound methodology which accounts for beverage type, the frequency and volume of consumption and patterns of use for alcohol remains an important research question. ${ }^{21}$ Recent reviews on the topic suggest that even light-to-moderate alcohol use may not be protective for chronic disease. ${ }^{21}$ This is contradictory to the messaging that currently exists surrounding alcohol consumption guidelines, which promote moderate alcohol consumption in those who choose to drink. ${ }^{3,22}$ Although the rates of past-year drinking among Canadians aged 15 years and older has decreased from $79 \%$ in 2004 to $76 \%$ in 2013, the rates of risky drinking behaviours have increased. ${ }^{23}$ For example, Canada's Low-Risk Drinking Guidelines ${ }^{24}$ recommend that women consume no more than 10 drinks per week (with no more than two drinks per day) and for men to consume no more than 15 drinks per week (with no more than three drinks per day). ${ }^{24,25}$ Despite these guidelines, the proportion of Canadians who exceed lowrisk drinking guidelines continues to rise. Compared to $13.0 \%$ in $2004^{26}, 17.6 \%^{27}$ and $20.0 \%{ }^{28}$ of those who drank alcohol (age 25 years and over) exceeded low-risk drinking guidelines for long-term health effects (e.g. cancer, epilepsy, pancreatitis, low birthweight, hemorrhagic stroke, dysrythmias, liver cirrhosis and hypertension) in 2012 and 2013, respectively.

Previous estimates of alcohol consumption prevalence in Alberta have come from national surveys on drug and alcohol use. ${ }^{26,28-34}$ Although cross-sectional data are available through national surveys, data on alcohol consumption in Alberta from a large prospective cohort were not previously available. The goal of these analyses was to characterize the levels of alcohol consumption among adults from Alberta's Tomorrow Project in the context of cancer prevention guidelines. Additionally, we identified sociodemographic factors associated with alcohol consumption patterns, its combined prevalence with tobacco use and high-risk profiles, and evaluated the proportion of participants exceeding the World Cancer Research Fund/American Institute of Cancer Research (WCRF/AICR) recommendations for alcohol consumption.

\section{Methods}

Alberta's Tomorrow Project is a prospective longitudinal cohort study established to examine the association between various lifestyle factors and chronic disease outcomes, and currently includes 55000 Albertans aged 35 to 69 years. Detailed information on recruitment methods for Alberta's Tomorrow Project have been published previously. ${ }^{35,36}$ In brief, Alberta's Tomorrow Project participants were recruited by random digit dialing (RDD) between 2001 and 2009. The RDD process resulted in 63486 interested individuals from which $48.8 \%$ enrolled into the cohort, resulting in 31072 participants. ${ }^{36}$ Participants completed self-administered questionnaires, including the Health and Lifestyle Questionnaire, the Diet History Questionnaire $^{37}$, and the Past Year Total Physical Activity Questionnaire. ${ }^{38,39}$ These questionnaires captured information about personal and family health history, cancer screening behaviours, diet and alcohol consumption, smoking habits and environmental exposures. These analyses examine only the first phase of recruited participants who completed the Health and Lifestyle Questionnaire and Diet History Questionnaire. Of the 31072 cohort participants who enrolled between 2001 and $2009,86 \%(n=26842)$ completed information on alcohol consumption.

\section{Assessment of alcohol and variables of interest}

Information on alcohol consumption was collected from 2001 to 2009 using a cognitive-based food frequency questionnaire (FFQ) developed by the United States National Cancer Institute as a tool for assessing nutrition over the preceding 12 months $^{40}$ and has been adapted for use in Canada. ${ }^{37}$ The Diet History Questionnaire (DHQ) was analyzed using Diet*Calc, version 1.4.2 (Canadian version) software. The DHQ has been validated across nutrients and food groups including alcohol. Additionally, numerous other well-designed studies have employed FFQs in their assessment of alcohol consumption. ${ }^{12,41,42}$ Participants were queried about consumption frequency and volume of beer, wine/ wine coolers, and liquors/mixed drinks during the past year. The questionnaire asked separately about cans/bottles of beer (12-ounce), glasses of wine/wine cooler (5-ounce), and drinks of liquor/ mixed drinks (1.5-ounce). Each beverage type had ten frequency response categories ranging from never to six or more servings (drinks) per day over the previous year. We estimated the average amount of ethanol consumed per week using the Canadian standard of $13.6 \mathrm{~g}$ of ethanol in a standard drink, corresponding to approximately $341 \mathrm{ml}$ of beer, $142 \mathrm{ml}$ of wine, and $43 \mathrm{ml}$ of liquor. ${ }^{43}$ It was not possible to garner information on heavy episodic drinking or whether participants typically drank on weekdays or weekends. We evaluated the proportion of participants who adhered to or exceeded the WCRF/AICR alcohol consumption recommendations for cancer prevention. ${ }^{44}$ Individuals were classified as those who adhered ( $\leq 2$ drinks/day for men; $\leq 1$ drink/ day for women) and those who exceeded recommendations ( $>2$ drinks/day for men; $>1 \mathrm{drink} /$ day for women).

To estimate the association between alcohol consumption patterns and tobacco use, we examined the proportion of men and women who adhered to or exceeded alcohol consumption guidelines across tobacco use groups. Tobacco use was captured from participant responses to self-report questionnaires at baseline. Participants were asked about their current and former tobacco use histories and were categorized as follows: never, former, current occasional and current daily smoker. Body Mass Index (BMI) was derived from participants' self-measured height and weight, and co-morbidity status was obtained from participants' self-reported physician diagnoses from the baseline questionnaire. To assess prevalence of multiple risk factors, we also considered the prevalence of tobacco smoking, body size (overweight or obesity, defined as body mass index [BMI] $>25 \mathrm{~kg} / \mathrm{m}^{2}$ ) and presence of comorbidity (defined as selfreport of a chronic disease including high blood pressure, angina, high cholesterol, heart attack, stroke, diabetes, polyps in the colon, ulcerative colitis, and cirrhosis of the liver). Multiple risk factors were categorized as none (participants met none of the criteria, i.e. were non-smokers, BMI 
$<25 \mathrm{~kg} / \mathrm{m}^{2}$ and reported no chronic conditions), low (met any one of the three criteria), moderate (two of three criteria) and high (all three criteria were met). We then examined the proportion of men and women who were within or exceeded lowrisk drinking guidelines within these graded risk categories.

\section{Statistical analysis}

Descriptive statistics were used to characterize consumption patterns within the cohort; we examined average consumption of alcohol $(0,0.1$ to $4.9,5$ to $14.9,15$ to $29.9,30$ to $44.9, \geq 45 \mathrm{~g} /$ day). Means and standard deviations (SD) were estimated for continuous variables, while frequencies and percentages were estimated for categorical variables. A kappa sensitivity analysis was conducted to determine the agreement between the Diet*Calc estimation of alcohol in number of drinks per day compared to grams of ethanol per day ( 1 drink $=13.6 \mathrm{~g}$ of ethanol). Pearson's chi-square tests were used for all comparison analyses. Additionally, multivariable logistic regression models were used to assess associations between sociodemographic characteristics and WCRF drinking recommendations. Missing data represented $<1 \%$ for all included variables. Missing values were omitted from analyses. All statistical tests were performed at a $5 \%$ level of significance using SAS version 9.2 (SAS Institute, Cary, NC, USA) on a Linux interface.

\section{Results}

\section{Alcohol Consumption Patterns}

The majority of participants (84\%, $\mathrm{n}=22627)$ reported consuming alcohol at some point in the preceding 12 months. Table 1 presents the proportion of Alberta's Tomorrow Project participants in each alcohol consumption category by sex and sociodemographic characteristics. Median (IQR) consumption of alcohol was 2.1 (5.8) g/day for women and 5.9 (14.8) g/ day for men. Compared to non-drinkers, men and women who consumed alcohol tended to be younger, consume more servings of red meat, be of European ethnicity, live in an urban setting, work full-time, and have a household income that exceeded \$80000 annually. A clear positive association was observed between daily consumption of alcohol and current tobacco use for both men and women.

\section{World Cancer Research Fund Drinking Recommendations for Cancer Prevention}

Table 2 presents the proportion of men and women that fell within or exceeded World Cancer Research Fund recommendations for personal alcohol consumption across demographic categories based on self-reported alcohol consumption. The majority ( $87 \%$ ) of cohort participants who reported consuming alcohol in the past 12 months fell within personal recommendations for alcohol consumption, while $13 \%$ of participants consumed alcohol in excess of recommendations. Slightly fewer women exceeded the drinking guidelines compared to men $(12.1 \%$ vs. $13.6 \%)$. A higher proportion of men exceeding the recommendations was observed for those who were more educated, had higher annual household incomes, who were middle aged (45 to 54 age group) and divorced/separated/widowed. Similar to men, women exceeding guidelines had higher household incomes, were employed full-time or retired, and were in the 45 to 54 year old age range.

Associations between WCRF drinking guidelines and sociodemographic characteristics are presented in Table 3. Overall, men and women with higher household incomes had higher odds of exceeding WCRF drinking guidelines. Additionally, participants who had ever smoked (current daily, current occasional and former smokers) had a higher odds of exceeding WCRF drinking guidelines compared to never smokers $(p<.0001)$. This was highest for men who were current daily smokers (OR, 95\% CI, 3.61, 3.00 to 4.36) and those who were current occasional smokers (OR, 95\% CI, 3.56, 2.63 to 4.82 ). Similar findings were observed for women who smoked daily (OR, 95\% CI, 3.06, 2.62 to 3.59 ) and occasionally (OR, $95 \%$ CI, 3.20, 2.43 to 4.21 ). Women who were of non-European or mixed ethnicity were less likely to exceed guidelines compared to women of European ethnic background (OR, 95\% CI, 0.66, 0.51 to 0.85 ).

\section{Drinking and other risk behaviour patterns}

As shown in Table 4, a higher proportion of non-smokers were observed among those who did not consume alcohol. A positive association was observed between current smoking status and total daily alcohol consumption. Volume of alcohol consumption was associated with multiple risk factor categories for both men and women.

Nearly $31.0 \%$ of men and $25.4 \%$ of women who exceeded guidelines were also current tobacco users (Table 5). The graded/multiple risk factor analysis revealed that a higher proportion of men exceeded the drinking guidelines and had moderate to high-risk profiles compared to women (56.0\% vs. $34.6 \%)$. Women who exceeded guidelines showed a slightly lower prevalence of multiple risk factors compared to women who fell within the guidelines (35\% vs. $37 \%$ ).

\section{Discussion}

We observed that the majority of cohort participants (84\%) consumed alcohol in the previous 12 months, which is slightly higher than that reported in other studies on alcohol use in Alberta $(76 \%)^{45}$ and Canada (77.1\%). ${ }^{46}$ Most participants who reported consuming alcohol in the past 12 months fell within alcohol consumption recommendations for low-risk drinking put forth by the World Cancer Research Fund/American Institute for Cancer Research (WCRF/AICR). However, it should be noted that the cohort only included adults 35 years and older, which excludes those aged 20 to 34 years, known to be the heaviest drinkers in Canada. ${ }^{23}$ Globally, the prevalence of alcohol consumption is rising and remains a public health concern. ${ }^{1}$ Excess alcohol consumption is widely recognized as a contributor to adverse health outcomes. ${ }^{1,5,6,8,9,22,47,48} \mathrm{~A}$ recent meta-analysis concluded that approximately 34000 cancer deaths worldwide could be attributed to "light" drinking (defined as: $\leq 12.5 \mathrm{~g}$ ethanol or $\leq 1$ drink per day) in 2004. ${ }^{49}$ The adverse effects of alcohol consumption on health may be underappreciated compared to that of tobacco use, but it has been suggested that the global burden of disease attributable to alcohol was similar to that attributable to smoking exposure in the year $2000{ }^{8,48}$ Recent findings do not support an overall protective effect from alcohol consumption. ${ }^{18,50-52}$ Flawed study designs have been implicated in earlier findings of "protective effects" ${ }^{53-58}$ - however, a great deal of controversy on this topic remains..$^{51,55,59-62}$

A large proportion of participants in this study reported light-moderate drinking (0.1 to $29.9 \mathrm{~g}$ of ethanol/day or $<1$ to 2 drinks/day), and may be unaware of the potential harm associated with even small 
TABLE 1

Characteristics of participants according to reported alcohol consumption patterns (g/day)

\begin{tabular}{|c|c|c|c|c|c|c|c|}
\hline \multirow{2}{*}{ Characteristics } & \multicolumn{6}{|c|}{ Total daily consumption of alcohol (g/day) } & \multirow{2}{*}{$p$-value } \\
\hline & $\mathbf{0}$ & $0.1-4.9$ & $5-14.9$ & 15-29.9 & $30-44.9$ & $\geq 45$ & \\
\hline Men & $n=1342$ & $\mathrm{n}=3327$ & $n=2708$ & $n=1546$ & $\mathrm{n}=433$ & $\mathrm{n}=758$ & \\
\hline European ethnicity (\%) & 69.5 & 73.8 & 76.8 & 78.1 & 80.1 & 76.1 & $<0.0001$ \\
\hline Family history of cancer (\%) & 51.3 & 48.6 & 51.0 & 53.0 & 54.3 & 52.6 & 0.0247 \\
\hline $\begin{array}{l}\text { History of colonoscopy or } \\
\text { sigmoidoscopy (\%) }\end{array}$ & 21.3 & 20.7 & 20.4 & 22.1 & 22.9 & 19.8 & 0.158 \\
\hline Current daily smoker (\%) & 12.5 & 12.4 & 12.5 & 15.7 & 18.7 & 31.1 & $<0.0001$ \\
\hline Post secondary completed (\%) & 52.6 & 55.2 & 59.6 & 59.8 & 56.4 & 52.0 & $<0.0001$ \\
\hline Household income $\geq \$ 80,000(\%)$ & 24.7 & 33.3 & 42.5 & 47.0 & 45.3 & 36.4 & $<0.0001$ \\
\hline Full-time occupational status (\%) & 68.6 & 74.3 & 79.2 & 75.3 & 73.9 & 76.8 & $<0.0001$ \\
\hline Married/living with a partner (\%) & 82.3 & 83.3 & 85.2 & 83.2 & 79.0 & 80.7 & 0.0024 \\
\hline Living in an urban area (\%) & 70.8 & 77.3 & 78.6 & 81.2 & 79.2 & 76.7 & $<0.0001$ \\
\hline Age (years) & $52.1(9.4)$ & $50.6(9.4)$ & $49.7(8.8)$ & $50.5(8.9)$ & $50.5(8.9)$ & $49.9(8.7)$ & $<0.0001$ \\
\hline Body mass index & $28.4(4.8)$ & $28.3(4.7)$ & $28.0(4.2)$ & $27.7(4.0)$ & $28.2(4.0)$ & $27.8(4.0)$ & $<0.0001$ \\
\hline $\begin{array}{l}\text { Recreational physical } \\
\text { activity (MET h/week) }\end{array}$ & $22.4(24.7)$ & $25.0(26.3)$ & $30.9(27.7)$ & $31.9(27.4)$ & $32.3(30.6)$ & $26.8(27.9)$ & $<0.0001$ \\
\hline $\begin{array}{l}\text { No. of pack-years among } \\
\text { ever smokers }\end{array}$ & $34.5(10.3)$ & $32.2(10.4)$ & $29.5(9.6)$ & $29.2(9.5)$ & $29.7(9.1)$ & $30.7(9.0)$ & $<0.0001$ \\
\hline $\begin{array}{l}\text { Calorie intake from sources } \\
\text { other than alcohol (kcal/day) }\end{array}$ & $2185.1(1110.6)$ & 2046.7 (878.9) & $2076.6(850.5)$ & $2084.6(820.2)$ & $2250.8(951.3)$ & 2495.7 (1059.1) & $<0.0001$ \\
\hline $\begin{array}{l}\text { Red meat in diet (no. } \\
\text { servings/week) }\end{array}$ & $5.7(5.2)$ & $5.4(4.2)$ & $5.8(4.1)$ & $6.1(4.1)$ & $6.8(5.2)$ & $7.7(5.5)$ & $<0.0001$ \\
\hline $\begin{array}{l}\text { Healthy Eating Index-Canada, } \\
2005^{\mathrm{b}}\end{array}$ & $51.1(9.6)$ & $50.8(9.3)$ & $50.9(8.7)$ & $50.5(8.3)$ & $50.6(8.0)$ & $50.3(7.5)$ & 0.272 \\
\hline Women & $n=2873$ & $n=8688$ & $n=3346$ & $n=1329$ & $n=201$ & $\mathrm{n}=291$ & \\
\hline European ethnicity (\%) & 72.9 & 77.8 & 80.2 & 80.4 & 83.1 & 85.2 & $<0.0001$ \\
\hline Family history of cancer (\%) & 55.5 & 55.2 & 52.9 & 54.7 & 54.7 & 51.2 & 0.2011 \\
\hline $\begin{array}{l}\text { History of colonoscopy or } \\
\text { sigmoidoscopy (\%) }\end{array}$ & 28.1 & 24.4 & 23.3 & 25.2 & 20.9 & 22.3 & 0.0002 \\
\hline Current daily smoker (\%) & 13.0 & 13.9 & 13.3 & 17.5 & 22.9 & 36.8 & $<0.0001$ \\
\hline Post-secondary completed (\%) & 41.6 & 47.7 & 55.0 & 52.0 & 44.8 & 38.1 & $<0.0001$ \\
\hline Household income $\geq \$ 80,000(\%)$ & 16.9 & 27.9 & 38.9 & 39.1 & 34.8 & 34.0 & $<0.0001$ \\
\hline Full-time occupational status (\%) & 34.1 & 45.4 & 47.5 & 46.0 & 52.7 & 50.5 & $<0.0001$ \\
\hline Married/living with a partner (\%) & 74.2 & 74.9 & 79.0 & 79.6 & 77.6 & 74.2 & $<0.0001$ \\
\hline Living in an urban area (\%) & 67.1 & 76.2 & 80.3 & 81.9 & 75.6 & 77.7 & $<0.0001$ \\
\hline Age (years) & $51.9(9.5)$ & $50.2(9.3)$ & $49.2(8.7)$ & $50.7(9.0)$ & $48.6(8.4)$ & $49.8(8.2)$ & $<0.0001$ \\
\hline Body mass index & $28.5(6.9)$ & $27.6(6.1)$ & $26.2(5.0)$ & $25.8(4.7)$ & $25.9(4.6)$ & $26.8(5.1)$ & $<0.0001$ \\
\hline $\begin{array}{l}\text { Recreational physical } \\
\text { activity (MET h/week) }\end{array}$ & $17.9(20.6)$ & $22.5(22.9)$ & $27.3(24.2)$ & $29.2(25.2)$ & $28.4(24.6)$ & $20.9(22.7)$ & $<0.0001$ \\
\hline $\begin{array}{l}\text { No. of pack-years among } \\
\text { ever smokers }\end{array}$ & $32.3(10.1)$ & $30.3(9.7)$ & $28.5(9.1)$ & $29.6(9.5)$ & $28.9(7.4)$ & $30.8(8.5)$ & $<0.0001$ \\
\hline $\begin{array}{l}\text { Calorie intake from sources } \\
\text { other than alcohol (kcal/day) }\end{array}$ & $1644.2(720.8)$ & $1574.9(634.0)$ & $1579.4(604.3)$ & $1613.4(629.7)$ & $1681.2(584.4)$ & 1782.8 (793.4) & $<0.0001$ \\
\hline $\begin{array}{l}\text { Red meat in diet (no. } \\
\text { servings/week) }\end{array}$ & $3.3(2.7)$ & $3.4(2.5)$ & $3.6(2.5)$ & $3.7(2.5)$ & $4.6(3.0)$ & $4.0(2.6)$ & $<0.0001$ \\
\hline
\end{tabular}

Continued on the following page 
TABLE 1 (continued)

Characteristics of participants according to reported alcohol consumption patterns (g/day)

\begin{tabular}{|c|c|c|c|c|c|c|c|}
\hline \multirow{2}{*}{ Characteristics } & \multicolumn{6}{|c|}{ Total daily consumption of alcohol (g/day) } & \multirow{2}{*}{$p$-value } \\
\hline & $\mathbf{0}$ & $0.1-4.9$ & $5-14.9$ & 15-29.9 & $30-44.9$ & $\geq 45$ & \\
\hline $\begin{array}{l}\text { Healthy Eating Index-Canada, } \\
2005^{\text {b }}\end{array}$ & $55.3(10.1)$ & $55.4(9.7)$ & $55.3(8.9)$ & $54.4(8.5)$ & $53.6(7.4)$ & $52.8(7.3)$ & $<0.0001$ \\
\hline Postmenopause (\%) & 45.4 & 53.7 & 58.1 & 51.3 & 62.2 & 50.5 & $<0.0001$ \\
\hline Current hormone therapy use (\%) & 16.3 & 14.8 & 13.8 & 17.0 & 10.5 & 15.1 & 0.0285 \\
\hline Mammogram in past 3 years (\%) & 79.9 & 81.5 & 82.3 & 85.7 & 81.4 & 74.9 & $<0.0001$ \\
\hline
\end{tabular}

Abbreviation: MET h/week, metabolic equivalent of task hours per week.

Notes: Mean (SD) was presented for continuous variables. Percentages were presented for categorical variables and as column percentages, i.e. $100 \%$ within each alcohol consumption category.

a $1 \mathrm{kcal}=4.18 \mathrm{~kJ}$.

${ }^{\mathrm{b}}$ Without alcohol intake.

'The chi-square test was used for categorical variables, and the one-way analysis of variance was used for continuous variables.

but regular amounts of alcohol. Further investigation into the relationship between low-risk drinking and health outcomes is essential to better characterize the exact risk-benefit threshold for alcohol consumption among different population groups. It is likely that current recommendations are not specific enough to account for inter-individual variation, susceptibility to particular disease, and tolerance thresholds.

As previously highlighted by the Pan American Health Organization and the WCRF, alcohol consumption behaviours differ considerably by sex. ${ }^{3,47}$ In the present study, men consumed alcohol more frequently and in greater quantities compared to women. Men were twice as likely to report daily drinking compared to women. This gender difference has been observed in previous population-based studies $^{3,47}$ and cross-national studies, ${ }^{63,64}$ which found higher prevalence of harmful alcohol consumption profiles among men, especially with respect to total volume consumed and risky patterns of use. ${ }^{63-65}$ Similar studies have also found that alcohol-attributable disease burden (i.e. cancer, cirrhosis of the liver, neuropsychiatric disorders, etc.) is five times higher in men than women, with a mortality ratio of 10:1 compared to women. ${ }^{8}$ The higher consumption observed in men could be attributable to biopsychosocial factors. ${ }^{63}$ Similarly, we observed that men were more likely to engage in both higher rates of alcohol consumption and tobacco smoking, amplifying their risk for adverse health outcomes and disease. Both men and women who exceeded drinking guidelines were more likely to use tobacco and have overall higher risk profiles compared to those who fell within current guidelines.

Preliminary analyses from this study suggests that some chronic conditions and comorbidities may be higher among those who exceed WCRF/AICR drinking recommendations, especially for men. Therefore, healthcare providers and public policy initiatives should work within the framework of risk-reduction to determine which strategies may be most appropriate for particular groups of individuals. Interventions targeted at specific populations who are known to have "at risk" alcohol consumption patterns are needed. Given the overwhelming evidence supporting a dose-risk relationship between alcohol and chronic disease, including cancer, public health messaging should continue to focus on limiting heavy drinking and supporting low-risk drinking for individuals who choose to drink, in addition to targeting individuals who may already have a high-risk profile. Future analyses using Alberta's Tomorrow Project will focus on investigating the association between long-term alcohol consumption patterns and incidence of cancer and other chronic diseases in this cohort.

TABLE 2

Proportion of Alberta's Tomorrow Project participants who fall within or exceed the World Cancer Research Fund/American Institute for Cancer Research alcohol consumption recommendations by sociodemographic characteristics ${ }^{\mathrm{a}}$

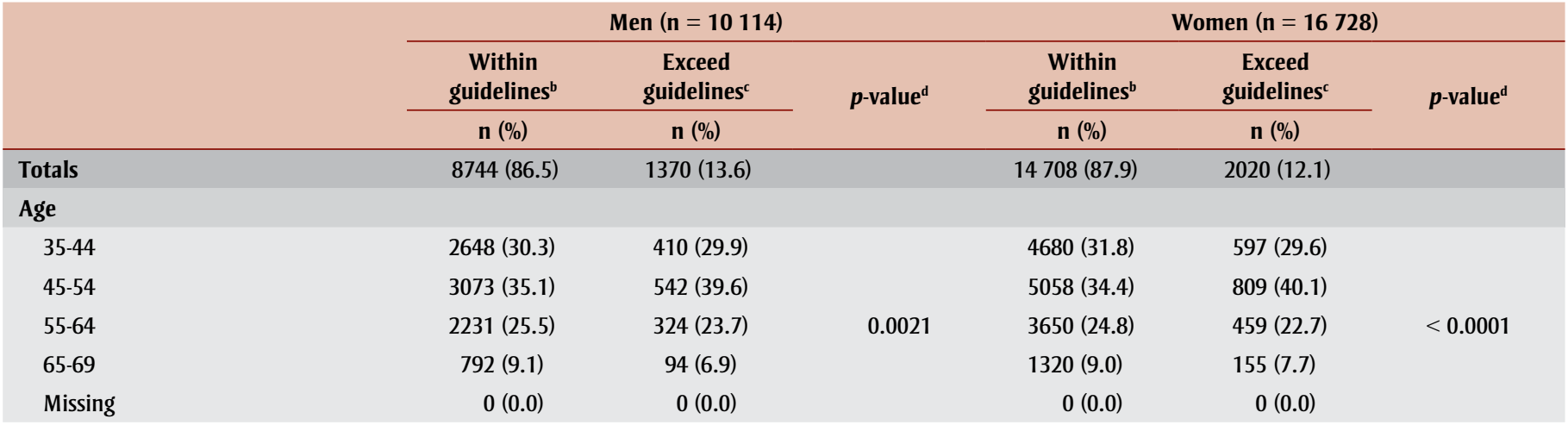


TABLE 2 (continued)

Proportion of Alberta's Tomorrow Project participants who fall within or exceed the World Cancer Research Fund/American Institute for Cancer Research alcohol consumption recommendations by sociodemographic characteristics ${ }^{\mathrm{a}}$

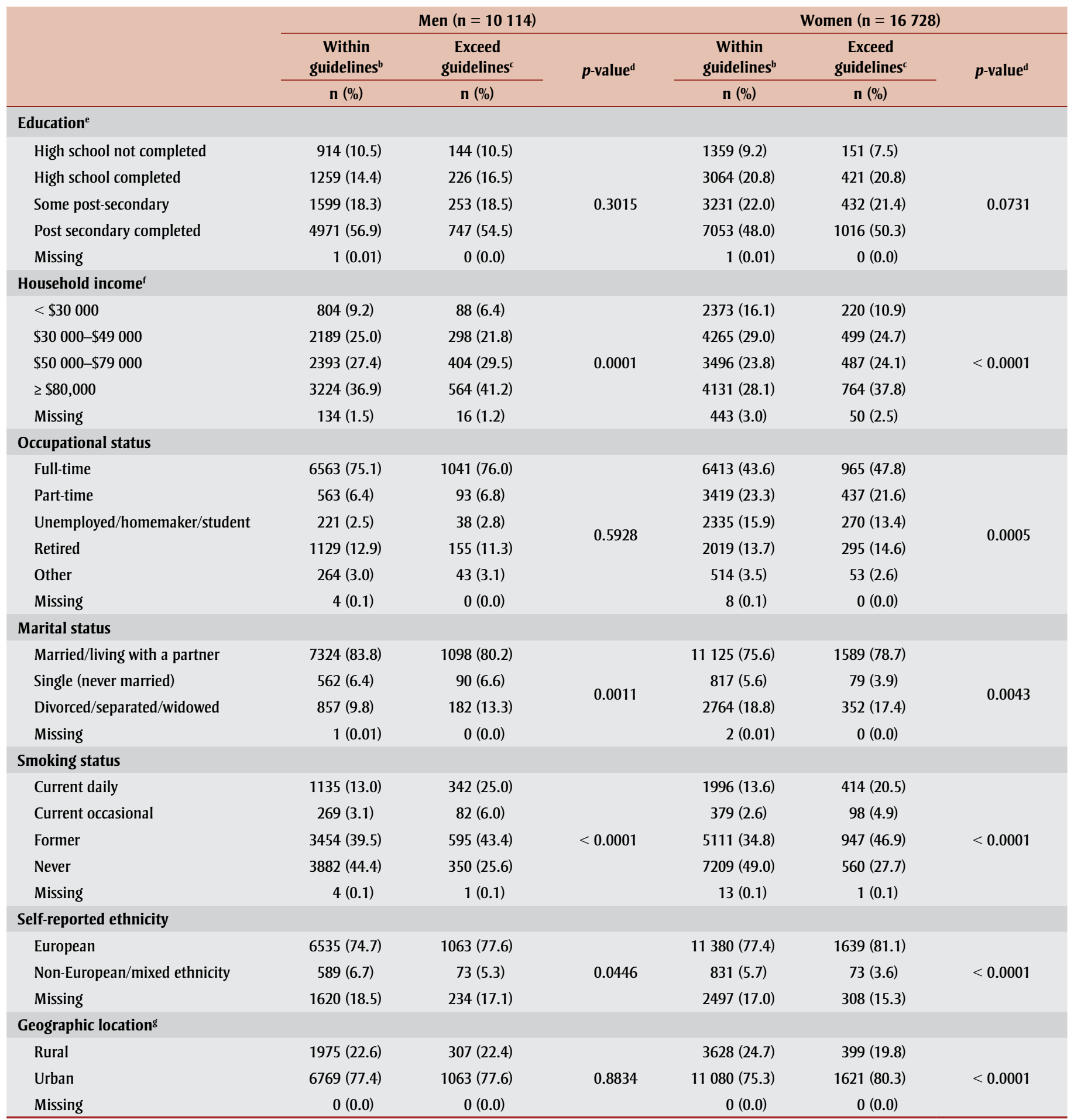

Note: Column percentages have been reported, i.e. $100 \%$ within each drinking guideline.

${ }^{a}$ Data presented as count and percentage.

${ }^{\mathrm{b}}$ Within Guidelines refers to $\leq 2$ drinks per day for men and $\leq 1$ drink per day for women.

' Exceeding Guidelines refers to $>2$ drinks per day for men and $>1$ drink per day for women.

${ }^{\mathrm{d}}$ Indicates statistically significant difference across sociodemographic categories in exceed and meet guidelines using chi-square tests $(p<0.001)$.

${ }^{\mathrm{e}}$ Combined responses to: some technical school/college, completed technical school/college, some university degree completed.

${ }^{\mathrm{f}}$ Income data are in response to a question about total household income before tax etc.

${ }^{8}$ Geographic location was determined using postal codes, where the " 0 " as the middle numerical number indicates rural residence. 
TABLE 3

Associations between WCRF alcohol intake guidelines and sociodemographic characteristics among participants in the Alberta's Tomorrow Project Cohort Study

\begin{tabular}{|c|c|c|c|c|c|c|c|c|}
\hline \multirow{2}{*}{ Variables } & \multicolumn{4}{|c|}{ Men } & \multicolumn{4}{|c|}{ Women } \\
\hline & OR & Lower & Upper & $p$-value & OR & Lower & Upper & $p$-value \\
\hline Age (years) & 0.99 & 0.98 & 1.01 & 0.0839 & 1.01 & 1.00 & 1.02 & 0.0221 \\
\hline Body mass index $\left(\mathrm{kg} / \mathrm{m}^{2}\right)$ & 0.99 & 0.97 & 1.01 & 0.1463 & 0.95 & 0.94 & 0.96 & $<0.0001$ \\
\hline Some post-secondary & 1.03 & 0.80 & 1.33 & 0.8217 & 1.12 & 0.89 & 1.42 & 0.326 \\
\hline Postsecondary completed & 1.04 & 0.82 & 1.30 & 0.7674 & 1.26 & 1.01 & 1.58 & 0.0414 \\
\hline High school not completed ${ }^{a}$ & 1.00 & \multicolumn{2}{|c|}{ Ref } & & 1.00 & \multicolumn{2}{|c|}{ Ref } & \\
\hline \multicolumn{9}{|l|}{ Household income } \\
\hline$\geq \$ 80000$ & 2.47 & 1.80 & 3.39 & $<0.0001$ & 1.86 & 1.51 & 2.30 & $<0.0001$ \\
\hline$<\$ 30000^{\mathrm{a}}$ & 1.00 & \multicolumn{2}{|c|}{ Ref } & & 1.00 & \multicolumn{2}{|c|}{ Ref } & \\
\hline \multicolumn{9}{|l|}{ Occupational status } \\
\hline Part-time & 1.24 & 0.95 & 1.63 & 0.1165 & 0.93 & 0.81 & 1.07 & 0.3081 \\
\hline Unemployed/homemaker/student & 1.14 & 0.76 & 1.70 & 0.5177 & 0.82 & 0.69 & 0.97 & 0.0198 \\
\hline Retired & 1.13 & 0.88 & 1.45 & 0.3528 & 1.07 & 0.88 & 1.29 & 0.5142 \\
\hline Other & 1.25 & 0.86 & 1.82 & 0.2388 & 0.75 & 0.54 & 1.05 & 0.096 \\
\hline Full-time $^{\mathrm{a}}$ & 1.00 & \multicolumn{2}{|c|}{ Ref } & & 1.00 & \multicolumn{2}{|c|}{ Ref } & \\
\hline Current occasional & 3.56 & 2.63 & 4.82 & $<0.0001$ & 3.20 & 2.43 & 4.21 & $<0.0001$ \\
\hline Former & 1.92 & 1.64 & 2.25 & $<0.0001$ & 2.51 & 2.22 & 2.84 & $<0.0001$ \\
\hline Never $^{\mathrm{a}}$ & 1.00 & \multicolumn{2}{|c|}{ Ref } & & 1.00 & \multicolumn{2}{|c|}{ Ref } & \\
\hline \multicolumn{9}{|l|}{ Self-reported ethnicity } \\
\hline Non-European or mixed ethnicity & 0.77 & 0.59 & 0.99 & 0.0479 & 0.66 & 0.51 & 0.85 & 0.0015 \\
\hline European $^{\mathrm{a}}$ & 1.00 & \multicolumn{2}{|c|}{ Ref } & & 1.00 & \multicolumn{2}{|c|}{ Ref } & \\
\hline Geographic location & & & & & & & & \\
\hline Rural & 0.99 & 0.84 & 1.16 & 0.8756 & 0.82 & 0.72 & 0.93 & 0.0027 \\
\hline Urban $^{\mathrm{a}}$ & 1.00 & & & & 1.00 & & & \\
\hline
\end{tabular}

Abbreviations: Cl, confidence interval; OR, odds ratio; Ref, reference category; WCRF, World Cancer Research Fund.

${ }^{a}$ Reference category. 
TABLE 4

The prevalence of self-reported alcohol consumption patterns and risk-related characteristics in Alberta's tomorrow Project cohort

\begin{tabular}{|c|c|c|c|c|c|c|c|}
\hline \multirow{3}{*}{ Risk factors } & \multicolumn{6}{|c|}{ Total daily consumption of alcohol ( $\mathrm{g} /$ day) } & \multirow{3}{*}{$p$-value ${ }^{d}$} \\
\hline & \multirow{2}{*}{$\begin{array}{c}0 \\
\text { n (\%) }\end{array}$} & \multirow{2}{*}{$\begin{array}{c}0.1-4.9 \\
n(\%)\end{array}$} & \multirow{2}{*}{$\begin{array}{c}5-14.9 \\
n(\%)\end{array}$} & \multirow{2}{*}{$\begin{array}{c}15-29.9 \\
n(\%)\end{array}$} & \multirow{2}{*}{$\begin{array}{c}30-44.9 \\
n(\%)\end{array}$} & \multirow{2}{*}{$\begin{array}{l}\geq 45 \\
\text { n (\%) }\end{array}$} & \\
\hline & & & & & & & \\
\hline Totals & 1342 (13.3) & 3327 (32.9) & $2708 \quad(26.8)$ & 1546 (15.3) & 433 (4.3) & 758 (7.5) & \\
\hline Never smoker & 612 (45.6) & 1609 (48.4) & 1183 (43.7) & 539 (34.9) & 129 (29.8) & 160 & \\
\hline $\begin{array}{l}\text { Current smoker (daily } \\
\text { or occasionally) }\end{array}$ & 189 (14.1) & 486 (14.6) & $451 \quad(16.7)$ & 312 (20.2) & 107 (24.7) & 283 (37.3) & $<0.0001$ \\
\hline Former smoker & $539 \quad(40.2)$ & $1230 \quad(37.0)$ & 1074 (39.7) & $695(45.0)$ & 196 (45.3) & 315 (41.6) & \\
\hline Missing & $2(0.2)$ & $2(0.1)$ & $0 \quad(0.0)$ & $\begin{array}{ll}0 & (0.0)\end{array}$ & $1 \quad(0.2)$ & $0 \quad(0.0)$ & \\
\hline $\mathrm{BMI}<25 \mathrm{~kg} / \mathrm{m}^{2}$ & 319 (23.8) & 789 (23.7) & $601(22.2)$ & $361(23.4)$ & 84 (19.4) & $173(22.8)$ & 033 \\
\hline $\mathrm{BMI} \geq 25 \mathrm{~kg} / \mathrm{m}^{2}$ & $1020(76.0)$ & $2529(76.0)$ & 2102 (77.6) & 1182 (76.5) & $348 \quad(80.4)$ & $582(76.8)$ & 0.3328 \\
\hline Missing & $3(0.2)$ & $9(0.3)$ & $5 \quad(0.2)$ & $3(0.2)$ & $1 \quad(0.2)$ & $3(0.4)$ & \\
\hline No comorbidities & $657(49.0)$ & 1707 (51.3) & $1495(55.2)$ & $793 \quad(51.3)$ & 205 (47.3) & $381 \quad(50.3)$ & \\
\hline Comorbidities $^{\mathrm{b}}$ & $683 \quad(50.9)$ & 1614 (48.5) & $1206 \quad(44.5)$ & 749 (48.5) & $227 \quad(52.4)$ & 376 (49.6) & 0.0005 \\
\hline Missing & $2(0.2)$ & $6 \quad(0.2)$ & $7 \quad(0.3)$ & $4 \quad(0.3)$ & $1 \quad(0.2)$ & $1(0.1)$ & \\
\hline No risk ${ }^{\mathrm{c}}$ & 160 (11.9) & 439 (13.2) & 353 (13.0) & 159 (10.3) & $36 \quad(8.3)$ & $43 \quad(5.7)$ & \\
\hline Low risk ${ }^{c}$ & $545 \quad(40.6)$ & 1333 (40.1) & 1125 (41.5) & $631 \quad(40.8)$ & $152 \quad(35.1)$ & 279 (36.8) & $<00001$ \\
\hline Moderate risk ${ }^{\mathrm{c}}$ & $564 \quad(42.0)$ & 1369 (41.2) & $1056 \quad(39.0)$ & $656 \quad(42.4)$ & 205 (47.3) & 346 (45.7) & \\
\hline High risk ${ }^{c}$ & $73 \quad(5.4)$ & $186(5.6)$ & $174 \quad(6.4)$ & $100 \quad(6.5)$ & $40 \quad(9.2)$ & $90 \quad(11.9)$ & \\
\hline \multicolumn{8}{|l|}{ Women } \\
\hline Totals & $2873 \quad(17.2)$ & $8688 \quad(51.9)$ & $3346 \quad(20.0)$ & 1329 (7.9) & $201 \quad(1.2)$ & $291 \quad(1.7)$ & \\
\hline Never smoker & $1636 \quad(56.9)$ & $4251 \quad$ (48.9) & $1385 \quad(41.4)$ & $413 \quad(22.4)$ & $45 \quad(22.4)$ & 39 (13.4) & \\
\hline $\begin{array}{l}\text { Current smoker (daily } \\
\text { or occasionally) }\end{array}$ & $400 \quad(13.9)$ & 1429 (16.5) & 582 (17.4) & 283 (21.3) & $67 \quad(33.3)$ & 126 (43.3) & $<0.0001$ \\
\hline Former smoker & $832 \quad(29.0)$ & $3001 \quad(34.5)$ & 1378 (41.2) & 632 (47.6) & 89 (44.3) & 126 (43.3) & \\
\hline Missing & $5 \quad(0.2)$ & $7 \quad(0.1)$ & $1 \quad(0.03)$ & $1 \quad(0.1)$ & $0 \quad(0.0)$ & $0 \quad(0.0)$ & \\
\hline $\mathrm{BMI}<25 \mathrm{~kg} / \mathrm{m}^{2}$ & $988 \quad(34.4)$ & 3331 (38.3) & 1593 (47.6) & $668 \quad(50.3)$ & 94 (46.8) & 113 (38.8) & $<00001$ \\
\hline $\mathrm{BMI} \geq 25 \mathrm{~kg} / \mathrm{m}^{2}$ & $1866 \quad(65.0)$ & $5332 \quad(61.4)$ & $1745 \quad(52.2)$ & 659 (49.6) & $106 \quad(52.7)$ & 177 (60.8) & 0.0001 \\
\hline Missing & $19(0.7)$ & $25 \quad(0.3)$ & $8 \quad(0.2)$ & $2(0.2)$ & $1 \quad(0.5)$ & $1 \quad(0.3)$ & \\
\hline No comorbidities & 1484 (51.7) & 5049 & $2161 \quad(64.6)$ & $802 \quad(60.4)$ & $129(64.2)$ & 168 (57.7) & $<00001$ \\
\hline Comorbidities $^{\mathrm{b}}$ & 1381 & 3624 (41.7) & 1178 (35.2) & $524 \quad(39.4)$ & 71 (35.3) & 122 (41.9) & \\
\hline Missing & $8 \quad(0.3)$ & $15 \quad(0.2)$ & $7(0.2)$ & $3(0.2)$ & $1(0.5)$ & $1(0.3)$ & \\
\hline No risk ${ }^{c}$ & $597 \quad(20.8)$ & 2021 & 988 (29.5) & 370 (27.8) & $46 \quad(22.9)$ & 39 (13.4) & \\
\hline Low risk ${ }^{c}$ & $1062(37.0)$ & 3355 (38.6) & 1334 (39.9) & $521 \quad(39.2)$ & 88 (43.8) & 112 (38.5) & $<00001$ \\
\hline Moderate risk ${ }^{\mathrm{c}}$ & 1057 (36.8) & 2906 & $901 \quad(26.9)$ & 369 (27.8) & $45 \quad(22.4)$ & 107 (36.8) & \\
\hline High risk ${ }^{c}$ & $157 \quad(5.5)$ & $406 \quad(4.7)$ & $123 \quad(3.7)$ & $69 \quad(5.2)$ & 22 (11.0) & 33 (11.3) & \\
\hline
\end{tabular}

Abbreviation: BMI, body mass index.

Note: Results have been presented as column percentages, ie. $100 \%$ within each alcohol consumption category.

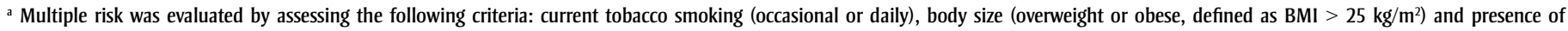
comorbidity.

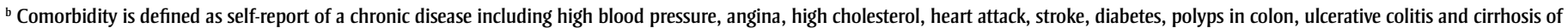
the liver.

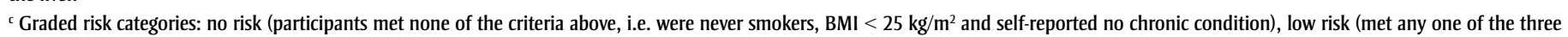
criteria shown above), moderate risk (met two of three criteria shown above) and high risk (met all three criteria shown above).

${ }^{\mathrm{d}}$ The chi-square test was used for categorical variables, and the one-way analysis of variance was used for continuous variables. 


\begin{tabular}{|c|c|c|c|c|c|}
\hline \multicolumn{6}{|c|}{ 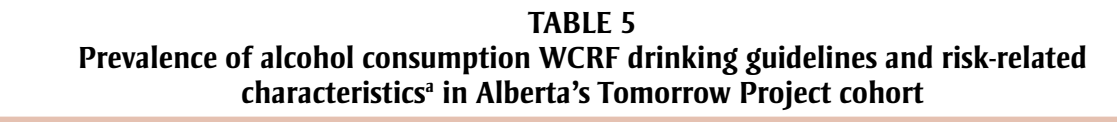 } \\
\hline \multirow{3}{*}{ Risk factors } & \multicolumn{4}{|c|}{ WCRF drinking guidelines ${ }^{b}$} & \multirow{3}{*}{$p$-value ${ }^{c}$} \\
\hline & \multicolumn{2}{|c|}{ Within guidelines } & \multicolumn{2}{|c|}{ Exceed guidelines } & \\
\hline & \multicolumn{2}{|c|}{ n (\%) } & \multicolumn{2}{|c|}{ n (\%) } & \\
\hline \multicolumn{6}{|l|}{ Men } \\
\hline Totals & 8744 & $(86.5)$ & 1370 & $(13.6)$ & \multirow{5}{*}{$<0.0001$} \\
\hline Never smoker & 3882 & $(44.4)$ & 350 & $(25.6)$ & \\
\hline Current smoker (daily or occasionally) & 1404 & $(16.1)$ & 424 & $(31.0)$ & \\
\hline Former smoker & 3454 & (39.5) & 595 & $(43.4)$ & \\
\hline Missing & 4 & $(0.1)$ & 1 & $(0.1)$ & \\
\hline $\mathrm{BMI}<25 \mathrm{~kg} / \mathrm{m}^{2}$ & 2025 & $(23.2)$ & 302 & $(22.0)$ & \multirow{3}{*}{0.3680} \\
\hline $\mathrm{BMI} \geq 25 \mathrm{~kg} / \mathrm{m}^{2}$ & 6699 & (76.6) & 1064 & $(77.7)$ & \\
\hline Missing & 20 & $(0.2)$ & 4 & $(0.3)$ & \\
\hline No comorbidities & 4560 & $(52.2)$ & 678 & $(49.5)$ & \multirow{3}{*}{0.0629} \\
\hline Comorbidities $^{\mathrm{d}}$ & 4165 & $(47.6)$ & 690 & $(50.4)$ & \\
\hline Missing & 19 & $(0.2)$ & 2 & $(0.2)$ & \\
\hline No risk & 1087 & (12.4) & 103 & $(7.5)$ & \multirow{4}{*}{$<0.0001$} \\
\hline Low risk & 3566 & $(40.8)$ & 499 & $(36.4)$ & \\
\hline Moderate risk & 3571 & $(40.8)$ & 625 & $(45.6)$ & \\
\hline High risk $^{\mathrm{e}}$ & 520 & $(6.0)$ & 143 & $(10.4)$ & \\
\hline \multicolumn{6}{|l|}{ Women } \\
\hline Totals & 14708 & (87.9) & 2020 & $(12.1)$ & \multirow{5}{*}{$<0.0001$} \\
\hline Non-smoker & 12320 & $(83.8)$ & 1507 & $(74.6)$ & \\
\hline Current smoker (daily or occasionally) & 2375 & $(16.2)$ & 512 & $(25.4)$ & \\
\hline Former smoker & 5111 & (34.8) & 947 & $(46.9)$ & \\
\hline Missing & 13 & $(0.1)$ & 1 & $(0.1)$ & \\
\hline $\mathrm{BMI}<25 \mathrm{~kg} / \mathrm{m}^{2}$ & 5814 & (39.5) & 973 & $(48.2)$ & \multirow{3}{*}{0.0035} \\
\hline $\mathrm{BMI} \geq 25 \mathrm{~kg} / \mathrm{m}^{2}$ & 8842 & $(60.1)$ & 1043 & (51.6) & \\
\hline Missing & 52 & $(0.4)$ & 4 & $(0.2)$ & \\
\hline No comorbidities & 8551 & (58.1) & 1242 & $(61.5)$ & \multirow{3}{*}{$<0.0001$} \\
\hline Comorbidities $^{d}$ & 6128 & (41.7) & 772 & (38.2) & \\
\hline Missing & 29 & $(0.2)$ & 6 & $(0.3)$ & \\
\hline No risk & 3540 & $(24.1)$ & 521 & $(25.8)$ & \multirow{4}{*}{$<0.0001$} \\
\hline Low risk & 5673 & (38.6) & 799 & (39.6) & \\
\hline Moderate risk & 4813 & (32.7) & 572 & $(28.3)$ & \\
\hline High risk ${ }^{\mathrm{e}}$ & 682 & (4.6) & 128 & (6.3) & \\
\hline
\end{tabular}

Abbreviations: BMI, body mass index; WCRF, World Cancer Research Fund.

Note: Results have been presented as column percentages.

a Multiple risk was evaluated by assessing the following criteria: tobacco smoking, body size (overweight or obese, defined as $\mathrm{BMI}>25 \mathrm{~kg} / \mathrm{m}^{2}$ ) and presence of comorbidity.

${ }^{b}$ Within guidelines refers to $\leq 2$ drinks per day for men and $\leq 1$ drink per day for women; exceeding guidelines refers to $>2$ drinks per day for men and $>1$ drink per day for women.

' The chi-square test was used for categorical variables, and the one-way analysis of variance was used for continuous variables.

d Comorbidity is defined as self-report of a chronic disease including high blood pressure, angina, high cholesterol, heart attack, stroke, diabetes, polyps in colon, ulcerative colitis and cirrhosis of the liver.

${ }^{\mathrm{e}}$ Graded risk categories: no risk (participants met none of the criteria above, i.e. were never smokers, $\mathrm{BMI}<25 \mathrm{~kg} / \mathrm{m}^{2}$ and selfreported no chronic condition), low risk (met any one of the three criteria shown above), moderate risk (met two of three criteria shown above) and high risk (met all three criteria shown above).

\section{Limitations}

It is important to acknowledge several limitations of the present study. Alberta's Tomorrow Project cohort does not include young adults ( $<35$ years), who have been shown to have a higher prevalence of alcohol consumption compared to middle-aged adults. ${ }^{31,34,66}$ Therefore, these estimates reflect only the adult population of Alberta between the ages of 35 and 69 years. While Alberta's Tomorrow Project was designed to be geographically representative of the adult population of Alberta, no weighted sampling strategy was used in the cohort design. Additionally, the initial recruitment through RDD methods resulted in a $48.4 \%$ response rate. It is unknown how responders differed from non-responders as no data were collected on those who did not enroll. While we believe that these results are largely generalizable to adults in Alberta, the data should not be considered representative of the Alberta population as a whole. The exclusion of Albertans under age 35 years may also account for the lower prevalence of Alberta's Tomorrow Project participants who exceed WCRF drinking recommendations compared to other national surveillance data. ${ }^{31,34,66}$ In addition, the results of the current analyses are based on participant responses to self-report surveys. Sensitive questions, such as those related to alcohol intake, can often lead to exposure misclassification due to underestimation and underreporting of true consumption. ${ }^{3,8}$ An unpublished analysis of the 2004 Canadian Addiction Survey found that respondents indicated they only drink on average one-third of what would be expected from official alcohol sales. ${ }^{67} \mathrm{~A}$ limitation of the use of the Diet History Questionnaire for the assessment of alcohol consumption is that it does not adequately capture heavy episodic or "binge" drinking habits, which may have led to an underestimation of total alcohol consumption. Numerous other well-designed studies have assessed alcohol consumption in a similar fashion, most notably the Nurses' Health Study ${ }^{41}$ and the Health Professionals Follow-up study ${ }^{12}$, both large ongoing prospective cohort studies. ${ }^{42}$

\section{Conclusion}

Despite the potential for underreporting, $84 \%$ of participants in the present study reported consuming alcohol in the past year. Men had a median (IQR) consumption of 5.9 (14.8) g/day of alcohol and 
women had a median consumption of 2.1 (5.8) g/day. Approximately $14 \%$ of men and $12 \%$ of women exceeded cancer prevention alcohol consumption recommendations. Additionally, higher volumes of alcohol consumption were found to be associated with tobacco use and elevated risk behaviour profiles in both men and women (all $p<$.0001). Public health messaging that continues to support minimal intake levels or low-risk drinking is essential in promoting moderation among individuals who choose to drink.

\section{Acknowledgements}

Alberta's Tomorrow Project is only possible due to the commitment of its research participants, its staff and its funders: Alberta Cancer Foundation, Canadian Partnership Against Cancer, Alberta Cancer Prevention Legacy Fund (administered by Alberta Innovates - Health Solutions) and substantial in kind funding from Alberta Health Services. The views expressed herein represent the views of the author(s) and not of Alberta's Tomorrow Project or any of its funders. The data product presented here from CCHS is provided 'as-is,' and Statistics Canada makes no warranty, either express or implied, including but not limited to, warranties of merchantability and fitness for a particular purpose. In no event will Statistics Canada be liable for any direct, special, indirect, consequential or other damages, however caused. Christine Friedenreich holds a Health Senior Scholar Award from Alberta Innovates-Health Solutions and the Alberta Cancer Foundation's Weekend to End Women's Cancers Breast Cancer Chair. Darren Brenner holds a Canadian Cancer Society Career Development Award in Cancer Prevention.

\section{Conflicts of interest}

There were no conflicts of interest declared.

\section{Authors' contributions and statement}

D.R.B., P.J.R. and C.M.F. were responsible for the study conception. C.M.F., D.R.B., P.J.R., A.E.P., T.R.H. and A.A. contributed substantially to the study design and interpretation of the data. A.A. completed the analyses. D.R.B and T.R.H. were major contributors in writing the manuscript. All authors read and gave final approval of this version to be published and agreed to be guarantors of the work.
The content and views expressed in this article are those of the authors and do not necessarily reflect those of the Government of Canada.

\section{References}

1. World Health Organisation. Global status report on alcohol and health 2014. 2014;1-392.

2. Danaei G, Vander Hoorn S, Lopez AD, Murray CJ, Ezzati M. Causes of cancer in the world: comparative risk assessment of nine behavioural and environmental risk factors. Lancet. 2005;366:1784-93.

3. World Cancer Research Fund/American Institute of Cancer Research (WCRF/ AICR). Food, nutrition, physical activity, and the prevention of cancer: a global perspective. World Cancer Res Fund Int 2007; 517.

4. IARC Monographs on the Evaluation of Carcvinogenic Risks to Humans PREAMBLE. 2006.

5. Fedirko V, Tramacere I, Bagnardi V, et al. Alcohol drinking and colorectal cancer risk: an overall and doseresponse meta-analysis of published studies. Ann Oncol. 2011;22: 1958-72.

6. Islami $\mathrm{F}$, Tramacere I, Rota $\mathrm{M}$, et al. Alcohol drinking and laryngeal cancer: overall and dose-risk relation asystematic review and meta-analysis. Oral Oncol. 2010;46: 802-10.

7. Baan R, Straif K, Grosse Y, et al. Carcinogenicity of alcoholic beverages. Lancet Oncol. 2007;8:292-93.

8. Rehm J, Room R, Monteiro M, et al. Chapter 12: Alcohol use. In: Alcohol. 2004, pp 959-1108.

9. Corrao G, Bagnardi V, Zambon A, La Vecchia C. A meta-analysis of alcohol consumption and the risk of 15 diseases. Prev Med (Baltim). 2004;38: 613-9.

10. Grundy A, Poirier AE, Khandwala F, McFadden A, Friedenreich CM, Brenner DR. Cancer incidence attributable to alcohol consumption in Alberta, Canada in 2012. Can Med Assoc J Open. 2016;4:E507-14.
11. Rimm EB, Klatsky A, Grobbee D, Stampfer MJ. Review of moderate alcohol consumption and reduced risk of coronary heart disease: is the effect due to beer, wine, or spirits. BMJ. 1996;312:731-36.

12. Rimm EB, Giovannucci EL, Willett WC, et al. Prospective study of alcohol consumption and risk of coronary disease in men. Lancet. 1991;338: 464-68.

13. Mukamal KJ, Jensen MK, Grønbæk $M$, et al. Drinking frequency, mediating biomarkers, and risk of myocardial infarction in women and men. Circulation. 2005;112:1406-13.

14. Collins MA, Neafsey EJ, Mukamal KJ, et al. Alcohol in moderation, cardioprotection and neuroprotection: epidemiological considerations and mechanistic studies. Alcohol Clin Exp Res. 2009;33:206-19.

15. Beulens JWJ, Van der Schouw YT, Bergmann MM, et al. Alcohol consumption and risk of type 2 diabetes in European men and women: Influence of beverage type and body size. The EPIC-InterAct study. J Intern Med. 2012;272:358-70.

16. Metcalf PA, Scragg RKR, Jackson R. Light to moderate alcohol consumption is protective for type 2 diabetes mellitus in normal weight and overweight individuals but not the obese. J Obes. 2014; 2014 . doi: $10.1155 / 2014 / 634587$.

17. Arranz S, Chiva-Blanch G, ValderasMartínez P, Medina-Remón A, Lamuela-Raventós RM, Estruch R. Wine, beer, alcohol and polyphenols on cardiovascular disease and cancer. Nutrients. 2012;4:759-81.

18. Connor J. Alcohol consumption as a cause of cancer. Addiction. 2016;103: 153-60.

19. Rehm J, Shield K. Alcohol consumption. In: Stewart BW, Wild CB E (ed). World Cancer Report 2014. International Agency for Research on Cancer: Lyon, France, 2014.

20. Klatsky AL, Udaltsova N, Li Y, Baer D, Nicole Tran H, Friedman GD. Moderate alcohol intake and cancer: the role of underreporting. Cancer Causes Control. 2014;25: 693-9. 
21. Toma A, Paré G, Leong DP. Alcohol and cardiovascular disease: how much is too much? Curr Atheroscler Rep. 2017;19:13.

22. Bagnardi V, Rota M, Botteri E, et al. Alcohol consumption and site-specific cancer risk: a comprehensive dose-response. Br J Cancer. 2014;112: 580-93.

23. Public Health Agency of Canada. The Chief Public Health Officer's Report on the State of Public Health in Canada 2015: Alcohol Consumption in Canada. Ottawa, Ontario, 2016. doi: $10.1177 / 1469605310365110$.

24. Butt P, Beirness D, Gliksman L, Paradis C, Stockwell T. Alcohol and health in Canada: A summary of evidence and guidelines for low-risk drinking. 2011. Available from: http:// www.ccsa.ca

25. The Canadian Centre on Substance Abuse. Canada's Low Risk Alcohol Drinking Guidelines. Alcohol Drink Guidel. 2013;4-5.

26. Health Canada. Canadian Addiction Survey (CAS): A national survey of Canadians' use of alcohol and other drugs (prevalence of use and related harms) highlights. Ottawa, Ontario, 2004. Available from: http://www .ccsa.ca/ResourceLibrary/ccsa-004804 -2004.pdf

27. Health Canada. Prevalence of alcohol use and exceeding low-risk drinking guidelines, by age, CAS 2004 and CADUMS 2008 - 2012. Can. Alcohol Drug Use Monit. Surv. 2014. Available from: http://www.hc-sc.gc.ca/hc-ps /drugs-drogues/stat/_2012/tables -tableaux-eng.php\#t9_fnb1-ref

28. Statistics Canada. Alcohol indicatiors by sex and age group, 2013 (table). Suppl. Tables, CTADS Annu. 2013 (February - December 2013). 2013. Available from: http://www.statcan .gc.ca/pub/12-591-x/2009001/02-step -etape/ex/ex-census-recensement-eng .htm

29. Statistics Canada. Canadian Community Health Survey: Detailed information for 2012. Available from: http://www 23 .statcan.gc.ca/imdb/p2SV.pl?Function $=$ getSurvey\&Id $=135927$
30. Statistics Canada. Canadian Community Health Survey: Detailed information for 2005 (cycle 3.1). 2006. Available from: http://www23.statcan.gc.ca/imdb /p2SV.pl?Function = getSurvey\&Id $=22642$

31. Health Canada. Canadian Alcohol and Drug Use Monitoring Survey (CADUMS), 2008. Available from: http://www.hc-sc.gc.ca/hc-ps/drugs -drogues/stat/_2008/summary -sommaire-eng.php

32. Health Canada. Canadian Alcohol and Drug Use Monitoring Survey (CADUMS), 2009. Available from: http://www.hc-sc.gc.ca/hc-ps/drugs -drogues/stat/_2009/summary -sommaire-eng.php

33. Health Canada. Canadian Alcohol and Drug Use Monitoring Survey (CADUMS), 2010. Available from: http://www.hc-sc.gc.ca/hc-ps/drugs -drogues/stat/_2010/summary -sommaire-eng.php

34. Health Canada. Canadian Alcohol and Drug Use Monitoring Survey (CADUMS), 2011. Available from: http://www.hc-sc.gc.ca/hc-ps/drugs -drogues/stat/_2011/summary -sommaire-eng.php

35. Bryant $\mathrm{H}$, Robson PJ, Ullman R, Friedenreich C, Dawe U. Populationbased cohort development in Alberta, Canada: a feasibility study. Chronic Dis Can. 2006; 27: 51-9.

36. Robson PJ, Solbak N, Haig T. Cohort profile: design, methods, and demographics from phase I of Alberta's Tomorrow Project cohort. Can Med Assoc J Open 4. 2016; E515-E527.

37. Csizmadi I, Kahle L, Ullman R, et al. Adaptation and evaluation of the National Cancer Institute's Diet History Questionnaire and nutrient database for Canadian populations. Public Health Nutr. 2007;10:88-96.

38. Friedenreich CM, Courneya KS, Bryant HE. The lifetime total physical activity questionnaire: development and reliability. Med Sci Sports Exerc. 1998;30:266-74.

39. Friedenreich CM, Courneya KS, Neilson HK, et al. Reliability and validity of the Past Year Total Physical Activity Questionnaire. Am J Epidemiol. 2006;163:959-70.
40. National Institutes of Health. Diet History Questionnaire. 2007.

41. Mostofsky E, Mukamal KJ, Giovannucci EL, Stampfer MJ, Rimm EB. Key findings on alcohol consumption and a variety of health outcomes from the Nurses' Health Study. Am J Public Health. 2016;106:1586-91.

42. Cao Y, Willett WC, Rimm EB, Stampfer MJ, Giovannucci EL. Light to moderate intake of alcohol, drinking patterns, and risk of cancer: results from two prospective US cohort studies. BMJ. 2015;351:h4238.

43. Centre for Addiction and Mental Health. Alcohol. [Internet]. Toronto (ON): CAMH; 2012 [accessed 4 Jan 2017]. Available from: http://www .camh.ca/en/hospital/health_ information/a_z_mental_health_and _addiction_information/alcohol /Pages/alcohol.aspx

44. World Cancer Research Fund/American Institute for Cancer Research. Food, Nutrition, Physical Activity, and the Prevention of Cancer: a Global Perspective. American Institute for Cancer Research: Washington DC, 2007 doi: 978-0-9722522-2-5.

45. Alberta Health Services. Alcohol and Health: Alcohol and Alberta. Edmonton, Alberta, 2015.

46. Canadian Centre on Substance Abuse. Alcohol. 2014.

47. Pan American Health Organization. Alcohol, gender, culture and harms in the Americas: PAHO Multicentric Study final report. [Internet]. Washington, DC, 2007 [accessed January 4, 2017]. Available from: http://www.who.int /substance_abuse/publications/alcohol _multicentric_americas.pdf

48. Rehm J, Mathers C, Popova S, Thavorncharoensap M, Teerawattananon Y, Patra J. Global burden of disease and injury and economic cost attributable to alcohol use and alcohol-use disorders. Lancet. 2009;373:2223-33.

49. Bagnardi V, Rota M, Botteri E, et al. Light alcohol drinking and cancer: A meta-analysis. Ann Oncol. 2013;24: 301-08. 
50. Chikritzhs T, Fillmore K, Stockwell T. A healthy dose of scepticism: four good reasons to think again about protective effects of alcohol on coronary heart disease. Drug Alcohol Rev. 2009;28:441-4.

51. Chikritzhs T, Stockwell T, Naimi T, Andreasson S, Dangardt F, Liang W. Has the leaning tower of presumed health benefits from 'moderate' alcohol use finally collapsed? (editorial). Addiction. 2015;110:726-27.

52. Stockwell T, Naimi T. Study raises new doubts regarding the hypothesised health benefits of 'moderate' alcohol use. Evid Based Med. 2016; 21:156.

53. Fekjaer HO. Alcohol-a universal preventive agent? A critical analysis. Addiction. 2013;108:2051-57.

54. Naimi TS, Stockwell T, Zhao J, et al. Selection biases in observational studies affect associations between 'moderate' alcohol consumption and mortality. Addiction. 2016. doi: 10.1111/add.13451.

55. Jackson R, Broad J, Connor J, Wells $\mathrm{S}$. Alcohol and ischaemic heart disease: probably no free lunch. Lancet. 2005;366:1911-12.

56. Naimi TS, Brown DW, Brewer RD, et al. Cardiovascular risk factors and confounders among nondrinking and moderate-drinking U.S. adults. Am J Prev Med. 2005;28:369-73.

57. Goldberg IJ. To drink or not to drink? N Engl J Med. 2003;348:163-4.

58. Naimi TS, Xuan Z, Brown DW, Saitz $R$. Confounding and studies of 'moderate' alcohol consumption: the case of drinking frequency and implications for low-risk drinking guidelines. Addiction. 2013;108:1534-43.

59. Roerecke M, Rehm J. Alcohol consumption, drinking patterns, and ischemic heart disease: a narrative review of meta-analyses and a systematic review and meta-analysis of the impact of heavy drinking occasions on risk for moderate drinkers. BMC Med. 2014;12:182.

60. Stockwell T. A reply to Roerecke \& Rehm: Continuing questions about alcohol and health benefits. Addiction. 2013;108:428-29.
61. Stockwell T, Chikritzhs T. Commentary: Another serious challenge to the hypothesis that moderate drinking is good for health? Int $\mathrm{J}$ Epidemiol. 2013;42:1792-94.

62. Bergmann MM, Rehm J, KlipsteinGrobusch K, et al. The association of pattern of lifetime alcohol use and cause of death in the European Prospective Investigation into Cancer and Nutrition (EPIC) study. Int $\mathrm{J}$ Epidemiol. 2013;42:1772-90.

63. Wilsnack RW, Vogeltanz ND, Wilsnack $\mathrm{SC}$, et al. Gender differences in alcohol consumption and adverse drinking consequences: cross-cultural patterns. Addiction. 2000;95: 251-65.

64. Wilsnack RW, Wilsnack SC, Kristjanson AF, Vogeltanz-Holm ND, Gmel G. Gender and alcohol consumption: patterns from the multinational GENACIS project. Addiction. 2009; 104:1487-500.

65. Hughes TL, Wilsnack SC, Kantor LW. The influence of gender and sexual orientation on alcohol use and alcohol-related problems: toward a global perspective. Alcohol Res. 2016;38: 121-32.

66. Sawka E, Huebert K, Malcolm C, Phare S, Adlaf E. Canadian Addiction Survey 2004: provincial differencesalcohol. 2007.

67. Stockwell T, Zhao J, Thomas G. Should alcohol policies aim to reduce total alcohol consumption? New analyses of Canadian drinking patterns. Addict Res Theory. 2009;17:135-51. 